\title{
Is partially automated driving, a bad idea? Observations from an on-road study
}

Victoria A. Banks ${ }^{\mathrm{a} *}$, Alexander Eriksson ${ }^{\mathrm{a} / \mathrm{b}}$, Jim O’Donoghue ${ }^{\mathrm{c}}$ \& Neville A. Stanton ${ }^{\mathrm{a}}$

*corresponding author: v.banks@soton.ac.uk

a Transportation Research Group, University of Southampton, UK

${ }^{\mathrm{b}}$ VTI Swedish National Road and Transport Research Institute, Sweden

c Jaguar Land Rover, i-House, Coventry, UK

The automation of longitudinal and lateral control has enabled drivers to become "hands and feet free" but they are required to remain in an active monitoring state with a requirement to resume manual control if required. This represents the single largest allocation of system function problem with vehicle automation as the literature suggests that humans are notoriously inefficient at completing prolonged monitoring tasks. To further explore whether partially automated driving solutions can appropriately support the driver in completing their new monitoring role, video observations were collected as part of an on-road study using a Tesla Model S being operated in Autopilot mode. A thematic analysis of video data suggests that drivers are not being properly supported in adhering to their new monitoring responsibilities and instead demonstrate behaviour indicative of complacency and over- trust. These attributes may encourage drivers to take more risks whilst out on the road.

\section{Highlights:}

- On-road study using a Tesla Model S operated in Autopilot mode

- Thematic analysis of driver behaviour highlights the impact of autonomous functionality on driver behaviour

- Findings reveal evidence of mode error, complacency and over- trust

Keywords: automated driving; driver role; level of automation; partial automation; mode transitions; transitions of control

\section{Introduction}

'Integrated Cruise Assist’ (Robert Bosch GmbH , 2015), ‘Autopilot’ (Tesla Motors, 2016a), 'Distronic Plus with Steering Assist' (Mercedes-Benz, 2013) and 'Intellisafe Autopilot' (Volvo Cars, 2016) are just some examples of automated driving features emerging into the 
marketplace that offer an enhanced level of automated driving functionality. According to the National Highway Traffic and Safety Administration (NHTSA, 2013), these systems use a combined function approach. This means that both longitudinal and lateral aspects of driving are automated simultaneously. More enhanced systems can also automate some of the traditional decision-making tasks of the driver (e.g. Walker et al, 2001, 2016). These systems can be seen as a form of ‘driver-initiated automation' whereby command and control supposedly remains within the drivers grasp (Banks \& Stanton, 2016). Theoretically, these systems enable the driver to become hands and feet free but not necessarily 'mind free' (Banks et al, 2014). Additional monitoring demands placed upon the driver in using such systems is a consequence of the fact that the driver is expected to be ready and prepared to act as a fall-back if the vehicle approaches the limits of its Operational Design Domain (ODD; SAE J3016, 2016). This essentially represents the Society of Automotive Engineers (SAE) Level 2 description of automated driving systems. Table 1 outlines the allocation of system function (i.e. responsibilities) of the driver and automated driving systems at each level of automation according to SAE. Acknowledgement of these roles and responsibilities is important as it helps to identify system limits and functional boundaries of system operation.

Table 1. Allocation of system function at different levels of automation based on SAE J3016 framework

\begin{tabular}{|l|c|c|c|c|c|}
\hline $\begin{array}{c}\text { Level of } \\
\text { Automation }\end{array}$ & $\begin{array}{c}\text { Longitudinal } \\
\text { and Lateral } \\
\text { Control }\end{array}$ & $\begin{array}{c}\text { Monitoring } \\
\text { of the } \\
\text { Environment }\end{array}$ & $\begin{array}{c}\text { Operational } \\
\text { \& Tactical } \\
\text { Tasks }\end{array}$ & $\begin{array}{c}\text { Strategic } \\
\text { Tasks }\end{array}$ & Examples \\
\hline $\begin{array}{l}\text { 0- No } \\
\text { Automation }\end{array}$ & D & D & D & D & $\begin{array}{c}\text { Warnings e.g. Blind Spot } \\
\text { Information Systems }\end{array}$ \\
\hline $\begin{array}{l}\text { 1- Driver } \\
\text { Assistance }\end{array}$ & D / A & D & D & D & Adaptive Cruise Control \\
\hline $\begin{array}{l}2-\text { Partial } \\
\text { Automation }\end{array}$ & A & D & D & D & Tesla Autopilot \\
Mercedes Distronic Plus
\end{tabular}

Key: $D=$ Driver; $A=$ Automation; $D / A=$ both driver and automation

The role of the driver throughout automation has however been a contentious issue. This is because SAE and other automation taxonomies (e.g. NHTSA, 2013; Gasser \& Westoff, 2012) do not formerly outline what the driver can and can not do under varying levels of autonomy. 
The role of the driver therefore is often left open to interpretation. Recently Banks \& Stanton (2017) discussed the varying roles of the driver within an automated driving system. A Driver Driving (DD) for example, would be responsible for completing basic, operational, tactical and strategic tasks of driving (Michon, 1985; Walker et al, 2015). The Driver Not Driving (DND) in contrast, would relinquish full control of these tasks to an automated subsystem. Whilst a transition between DD and DND may be appropriate for some driving modes, there is a risk that this transition may also occur at lower levels of the automation despite countermeasures being put in place. During the intermediate levels of automation, Banks \& Stanton (2017) suggest that the driver should assume a monitoring role (e.g. Driver Monitor; $\mathrm{DM})$. For SAE Level 2 systems, it is vital that driver mode transitions are only made between DD and DM (and vice versa) to ensure that system safety can be appropriately maintained. A transition between DD and DND is considered to be problematic at Level 2 because automated systems are not capable of functioning during all possible driving modes (Norman, 1990). However, the perception of increased reliability, leads drivers to become more complacent in system operation and it may mean that they do not monitor the system as closely as they should (Molloy \& Parasuraman, 1996; Parasuraman et al, 1993). Reductions in awareness may increase the occurrence of mode errors (Sarter \& Woods, 1995) and automation surprises (Sarter et al, 1997) in situations whereby the automated system is unable to cope with its current environment. Thus, we may begin to see the emergence of the DND role at lower ends of the automation taxonomy.

"Driver error" was identified as the probable cause of a fatal incident involving a Tesla Model S being operated in Autopilot mode in Florida, 2016 (National Highway Traffic \& Safety Administration, 2017). Since then, more evidence has surfaced that suggests there is a major discrepancy in the design philosophies underpinning automobile automation innovation. Despite issues relating to sustained attention, fatigue, trust, reduced situation awareness, decreased response times, cognitive overload and underload that have been consistently highlighted as problems within human-computer interaction (e.g. Dozza, 2012; Molloy \& Parasuraman, 1996; Stanton et al, 1997), partial automation is reliant on humans completing a sustained monitoring task. To explore whether or not enhanced Level 2 systems can appropriately support the additional monitoring responsibilities of the driver, a thematic analysis of video data captured during a previous study by Eriksson et al, (2017) was conducted. This study made use of a Tesla Model S, being operated in Autopilot mode, on the open road. Video cameras were used to capture additional data relating to the nature of control mode transitions between manual and automated driving. The purpose of the following analysis was to highlight the impact of autonomous functionality upon driver behaviour and identify specific areas that could be indicative of compromised system safety. To date, very few studies have assessed natural driving behaviours in an on road setting with enhanced SAE Level 2 systems. Some notable exceptions include Banks \& Stanton (2015; 2016), Naujoks et al. (2016), Endsley (2017) and Stapel et al. (2017). However, previous investigations have typically been limited to closed-loop circuits (Eriksson, 2017).

\section{Method}

Participants 
Twelve participants between the ages of 20 and 49 years $(M=32.33, S D=10.98)$ were recruited to take part in this study. They had an average $14.58(S D=11.13)$ years driving experience, an average of approximately 10.000-20.000 kilometre driving distance per year (3 reported lower driving distance, and 1 reported a higher value) and all had experience in using Advanced Driver Assistance Systems such as Adaptive Cruise Control and Lane Keeping Assist. The study complied with the British Psychological Society's Code of Ethics and had been approved by the University of Southampton Ethics Research and Governance Office (ERGO: 19151).

\section{Experimental Design and Procedure}

Upon providing informed consent, participants were invited to drive along public roads and highways (B4100, M40, M42) within Warwickshire in a right hand drive Tesla Model S P90 equipped with the Autopilot version 7.x software. Drivers were reminded that they were responsible for safe operation of the vehicle regardless of its mode (manual or automated) in line with recent amendments to the Vienna Convention of Road Traffic (United Nations, 1968) and were also advised to adhere to the Highway Code throughout the journey (Department for Transport, 2015). Drivers were not actively encouraged to remove their hands from the steering wheel at any time but were encouraged to drive in a manner they felt comfortable. They were further told that this exercise was not a test of their driving ability. To support them in remaining aware of the vehicles internal Human Machine Interface (HMI), a qualified safety driver was present in the passenger seat throughout the duration of the study. The safety driver was responsible for prompting participants to regain manual control of the vehicle if they failed to respond to the automated warnings, or, pressing the emergency stop button on the centre display if they felt that the safety of the vehicle occupants or other road users was at risk.

Participants were given a brief introduction into the functionality and controls of the Tesla Autopilot system. This included ways in which the Autopilot system could be overridden as well as the meaning of images displayed on the internal HMI (in line with the Model S Owner’s Manual, Tesla Motors, 2016b). No further training was provided given that new vehicle customers are not offered additional training in relation to the use of automated vehicle subsystems at point of sale. The researchers felt that this introduction to the Autopilot feature was sufficient.

Throughout the duration of the drive (approximately 40 minutes), video and audio recordings were captured using Racelogic video VBOX equipment. This comprised of four synchronised cameras; 2 facing the driver HMI (control stork, and instrument cluster), 1 road facing camera, and 1 attached centrally to the glass roof behind the driver and passenger seats. The duration of the drive was deemed to be representative of an approximate one-way commute the National Travel Survey (Department for Transport; DfT, 2017) shows that the average daily commute is 30 minutes.

\section{Data reduction and thematic analysis}

The video data was subjected to a thematic analysis using a data-driven approach. The final coding scheme consisted of four main themes (see Table 2). These categories were chosen as they serve to highlight potential issues within the driver-vehicle-world interaction patterns for 
enhanced SAE Level 2 systems such as Tesla's Autopilot. Two videos were selected at random and subjected to further analysis by a secondary coder using the same coding scheme. Inter-rater reliability was calculated and scored above 90\% agreement (Lombard et al. 2002; Marques and McCall, 2005).

Table 2. Coding scheme and descriptions used to analyse video data along with frequency counts

\begin{tabular}{|c|c|c|c|c|}
\hline Theme & Sub-theme & Description & Frequency & $\begin{array}{l}\text { Number of } \\
\text { participants }\end{array}$ \\
\hline \multirow[t]{4}{*}{$\begin{array}{l}\text { Occurrence of system } \\
\text { warnings }\end{array}$} & 'Hold steering wheel' & $\begin{array}{l}\text { Visual message presented } \\
\text { on HMI }\end{array}$ & 20 & 11 \\
\hline & $\begin{array}{l}\text { Escalating 'Hold } \\
\text { steering wheel' }\end{array}$ & $\begin{array}{l}\text { Sounding of an auditory } \\
\text { warning accompanying } \\
\text { visual display }\end{array}$ & 7 & 5 \\
\hline & $\begin{array}{l}\text { 'Collision warning' / } \\
\text { AEB warning }\end{array}$ & $\begin{array}{l}\text { Visual indicator presented } \\
\text { on HMI combined with an } \\
\text { auditory warning. HMI } \\
\text { begins to flash as 'threat' } \\
\text { gets closer }\end{array}$ & 1 & 1 \\
\hline & $\begin{array}{l}\text { 'Take over } \\
\text { immediately' }\end{array}$ & $\begin{array}{l}\text { Visual message presented } \\
\text { on HMI combined with an } \\
\text { auditory warning. Is used } \\
\text { when ODD limits have } \\
\text { been exceeded. }\end{array}$ & 2 & 2 \\
\hline \multicolumn{2}{|c|}{ Testing the boundaries of ODD } & $\begin{array}{l}\text { Drivers intentionally test } \\
\text { the limits of automated } \\
\text { functionality }\end{array}$ & 2 & 2 \\
\hline \multicolumn{2}{|l|}{ Mode confusion } & $\begin{array}{l}\text { Drivers say that the system } \\
\text { is in one mode when it is } \\
\text { actually in another }\end{array}$ & 5 & 4 \\
\hline \multicolumn{2}{|c|}{ Engagement in non-driving related secondary tasks } & $\begin{array}{l}\text { Any activity that is not } \\
\text { associated with the driving } \\
\text { task (e.g. drinking coffee) }\end{array}$ & 3 & 2 \\
\hline
\end{tabular}

\section{Results}

The following section discusses each key theme in turn;

\section{Occurrence of system warnings}

It is clear that the most prominent theme occurring throughout the study was the presentation of system warnings, specifically the 'Hold steering wheel' visual warning within the HMI. This suggests that prolonged "hands free" driving (over 60 seconds) was observed for the majority of participants on more than one occasion. Only one participant remained exclusively "hands on" regardless of whether Autopilot was engaged or not. For the remainder of participants, they spent at least one or more occasion driving "hands free" for 60 seconds. Note, that the visual warning at the time of study only became active following 60 seconds of driver inactivity.

Seven of these warnings escalated further - an auditory tone was signalled 15 seconds after the initial visual warning. At this stage, drivers would have been "hands free" for over 75 
seconds. This represents a substantial time period that could enable non-driving related secondary tasks to be completed. If this were to occur, drivers would find themselves being in the role of DND (Banks \& Stanton, 2017) - something that could have disastrous consequences in the event of ODD limits being reached or system malfunction. The fatal Tesla incident in May 2016 for example, was attributed to a prolonged period of distracted driving (NHTSA, 2017).

Whilst the frequency of system warnings could be argued to be fairly small considering the length of the experimental journeys (equating to 21.75 minutes of "hands free" out of approximately 8 hours of driving, we must reiterate that this data was collected as part of Eriksson et als' (2017)study investigating user-paced transfer of control. Participants were therefore prompted to relinquish and resume control at certain points throughout the drive an acknowledged weakness of this analysis. Even so, these more naturalistic periods of automated driving signal that a) all but one driver spent at least one part of their journey completely "hands free" b) the initial visual warning associated with inappropriate use of the system was not salient enough to get the drivers attention and c) the escalation in warning, via the use of an auditory tone, did prompt drivers in most cases to put their hands back on the wheel. However, the observations made in this study also suggest that the auditory tone could have potential to create confusion or startle effects (Sarter et al, 1997). For example, the storyboard presented in Figure 1 clearly shows that as soon as the Autopilot was engaged, the participant became completely "hands-free". The driver appeared at ease and appeared to be engaged in monitoring activities external to the vehicle. After 60 seconds, a visual warning was presented in the HMI that instructed them to place their hands back on the wheel. This went completely unnoticed for 15 seconds before an auditory tone was sounded. At this point, the driver appeared confused signalling the occurrence of a mode confusion (Sarter et al, 1997). The ability of the driver to respond in this situation was weakened as their awareness surrounding system state was compromised. This is because they failed to monitor the status of the internal HMI during this period of driving. This therefore represents an inherent paradox within the design of enhanced Level 2 systems. Whilst awareness of the external environment may be improved with the addition of Autopilot, reductions in in-vehicle glances may lead to less awareness relating to system status. In this instance, the safety driver had to prompt the driver to look at the internal HMI and instructed them to place their hands back on the wheel in order to cope with the situation. An additional 2 seconds passed before the driver did this. In total then, this participant spent 77 seconds completely "hands free". Whilst it is possible that improved familiarity with the system would limit the occurrence of mode confusion and startle effects (Sarter et al, 1997), the single case study conducted by Endsley (2017) indicates that even with experience, such performance decrements may still occur, despite familiarity with the associated human factors issues pertinent in vehicle automation. This is likely to be partly attributable to the continued updates being made to the system that deliver subtle changes to system operation. What is of greatest concern however, is the occurrence of mode confusions despite the driver being alert and well-motivated to remain in control of the vehicle. 


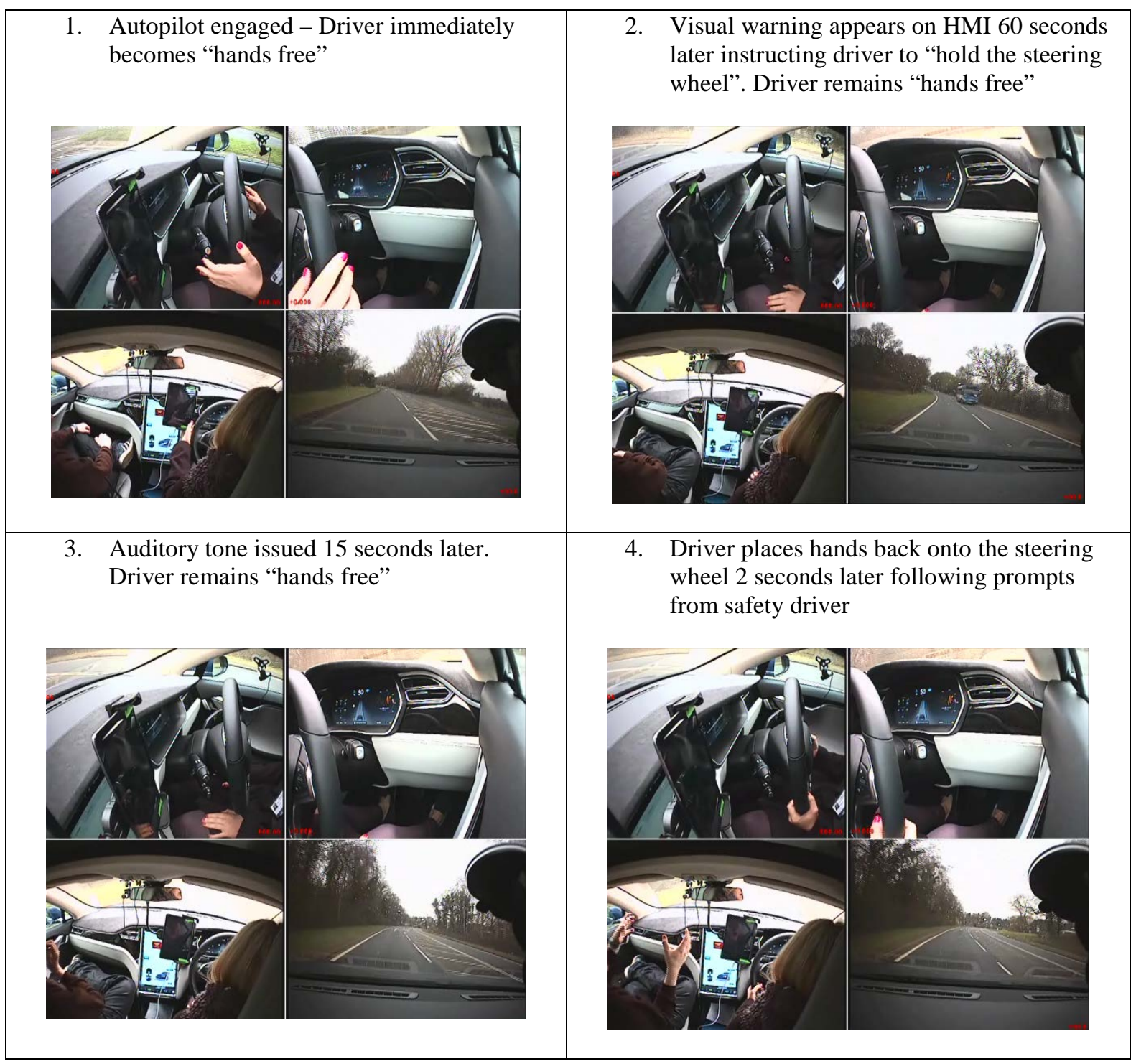

|Figure 1. Evidence of an extended period (77 seconds) of "hands free” driving despite visual and auditory warnings

It is important to note, that like many other vehicles, the Tesla Model S is also equipped with collision warning systems. These are designed to alert the driver to potential hazards within the road environment. Whilst it was not anticipated that any collision warnings would occur during this study, the thematic analysis reveals that a single collision warning was documented. The storyboard presented in Figure 2 shows the circumstances surrounding this situation. The Tesla was being driven in Autopilot mode at the time but the driver remained 'hands on'. The car ahead was stationary in a right hand turn lane. Whilst for a manual driver this would not be deemed as a hazardous situation, the Autopilot detected this as a threat and activated a combined auditory and visual alert. The driver was already in a position to regain control of the vehicle and quickly overrode the Autopilot. Interestingly, for the remainder of this drive, the driver did not reactivate the Autopilot feature instead choosing to drive the vehicle manually. It seems likely that such an incident could challenge the developing working mental models of system functionality. Here is a clear example of dissonance 
between what the driver would normally do and what the system actually did. These types of 'false alarm' have the potential to negatively impact upon the development of trust in system operation (e.g. Johnson et al, 2004). If these false alarms continue to happen, drivers may choose not use the system at all (Parasuraman \& Riley, 1997).

1. Autopilot detects hazard ahead. Auditory warning sounds and visual indicator is displayed on HMI (highlighted by red box)

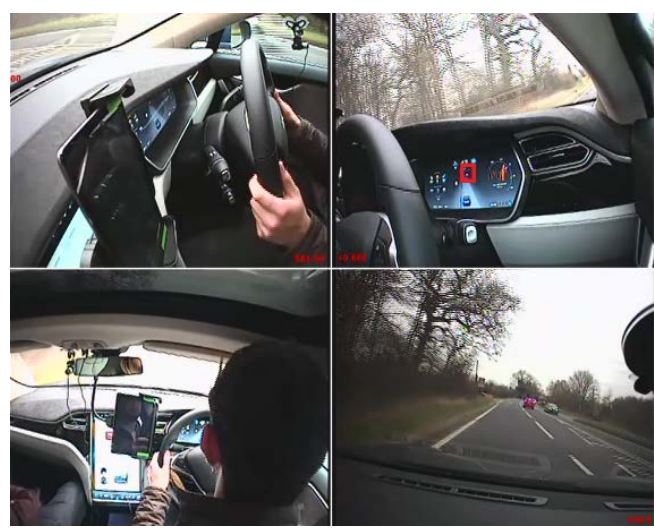

2. Area immediately in front of host vehicle representation in HMI turns red and begins to flash. Driver has overridden Autopilot and vehicle is now in manual mode

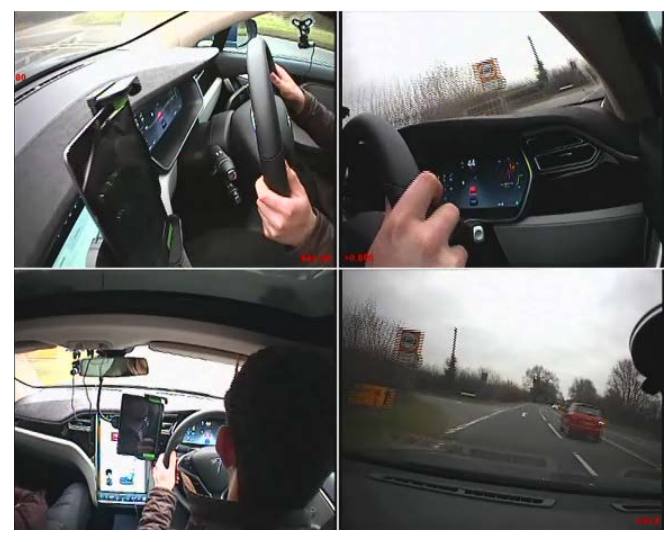

Figure 2. Storyboard showing events surrounding the activation of a collision warning

\section{Testing the boundaries of ODD}

The intentional testing of Autopilots ODD boundaries was observed twice throughout the study. This demonstrates that humans have a natural curiosity to test system limits despite strict instruction to remain in control of the vehicle. Figure 3 presents a storyboard example of the events surrounding one situation in which a participant tested the Autopilots ODD boundaries. In this example, the driver attempted to leave the carriageway whilst in Autopilot mode. Whilst they demonstrated strong monitoring behaviour and kept their hands hovering by the steering wheel poised to regain control, they were clearly engaging in risky behaviour. What is more, the driver failed to realise that a small torque input had actually deactivated the Autopilot feature and their hands remained hovering over the steering wheel despite being in manual mode. This is therefore indicative of a mode confusion as the driver thought the vehicle was in Autopilot mode when actually it was in Manual mode. With the vehicle failing to leave the carriageway as desired, the driver placed their hands fully back on the wheel whilst paradoxically stating;

\section{"Don't worry, I had a handle on it"}

completely unaware of their error. 


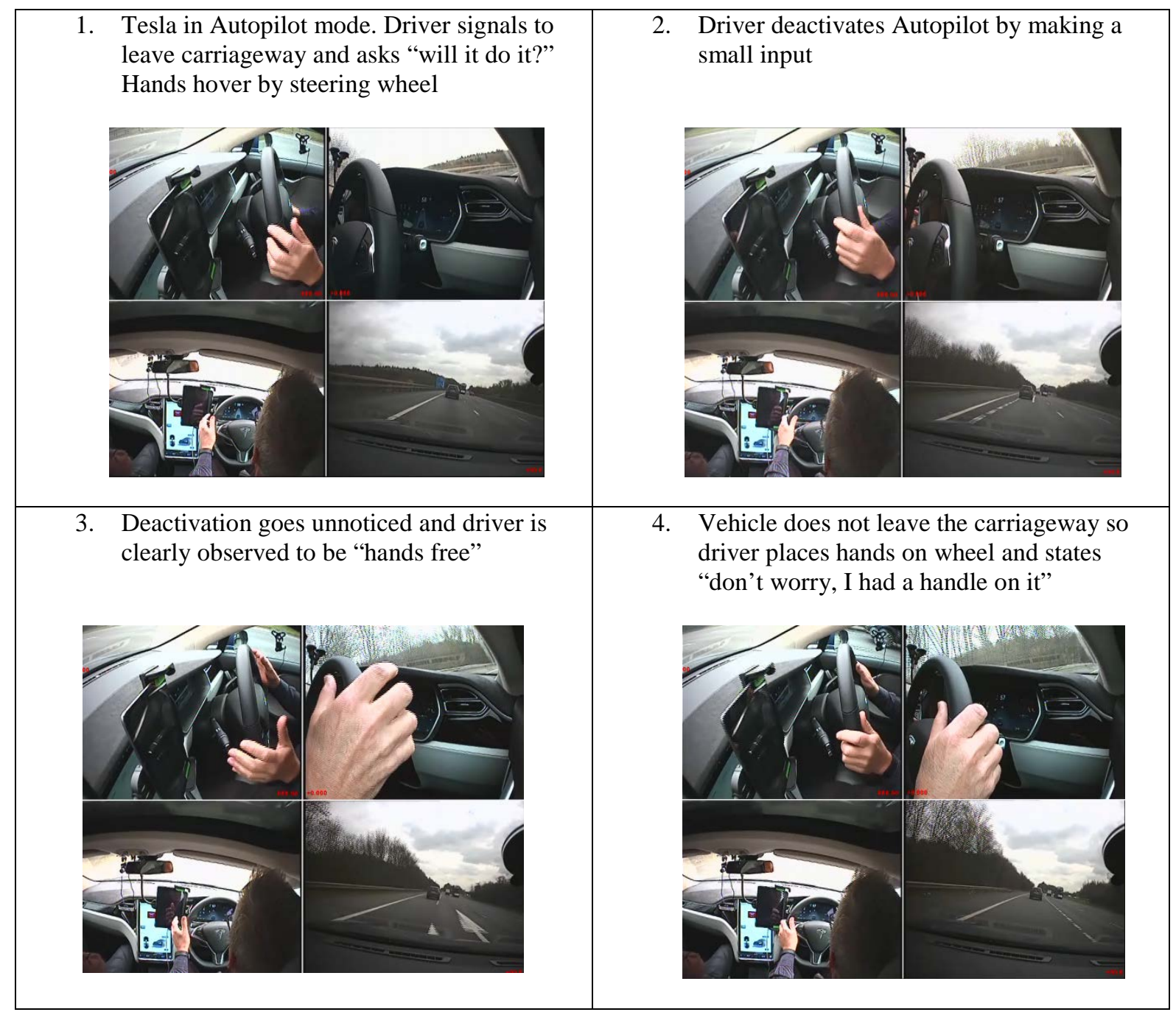

Figure 3. Evidence of a driver testing the ODD boundaries of Tesla's Autopilot

\section{Mode confusion}

All of the mode confusions that were observed within this study were based upon the driver failing to understand what mode the vehicle was driving in (i.e. thinking that Autopilot was engaged when actually it was not). In the storyboard example presented in Figure 4, the driver attempted to engage Autopilot using the control stork indicators. The driver then released their grip from the steering wheel because they thought the Autopilot feature was engaged despite the HMI indicating otherwise. Upon closer inspection of the internal HMI, the driver quickly realised their mistake and regained control of the steering wheel. If we think of this in terms of the changing driver role, the intention was that the driver would go from active operator (i.e. DD) to monitor (i.e. DM). However, the driver quickly realised that this control transition had not been successful and resumed back to the DD role. Other causes of mode confusion within this study were inadvertent torque inputs (i.e. the driver did not realise they had deactivated Autopilot), failure to properly engage Autopilot in the first instance, and misunderstanding of the internal HMI - perhaps indicative of a system transparency issue (e.g. Banks \& Stanton, 2016). The occurrence of mode confusion suggests that overall system safety could be compromised during such instances, especially if drivers believe they are in automated mode when actually, they are not. 


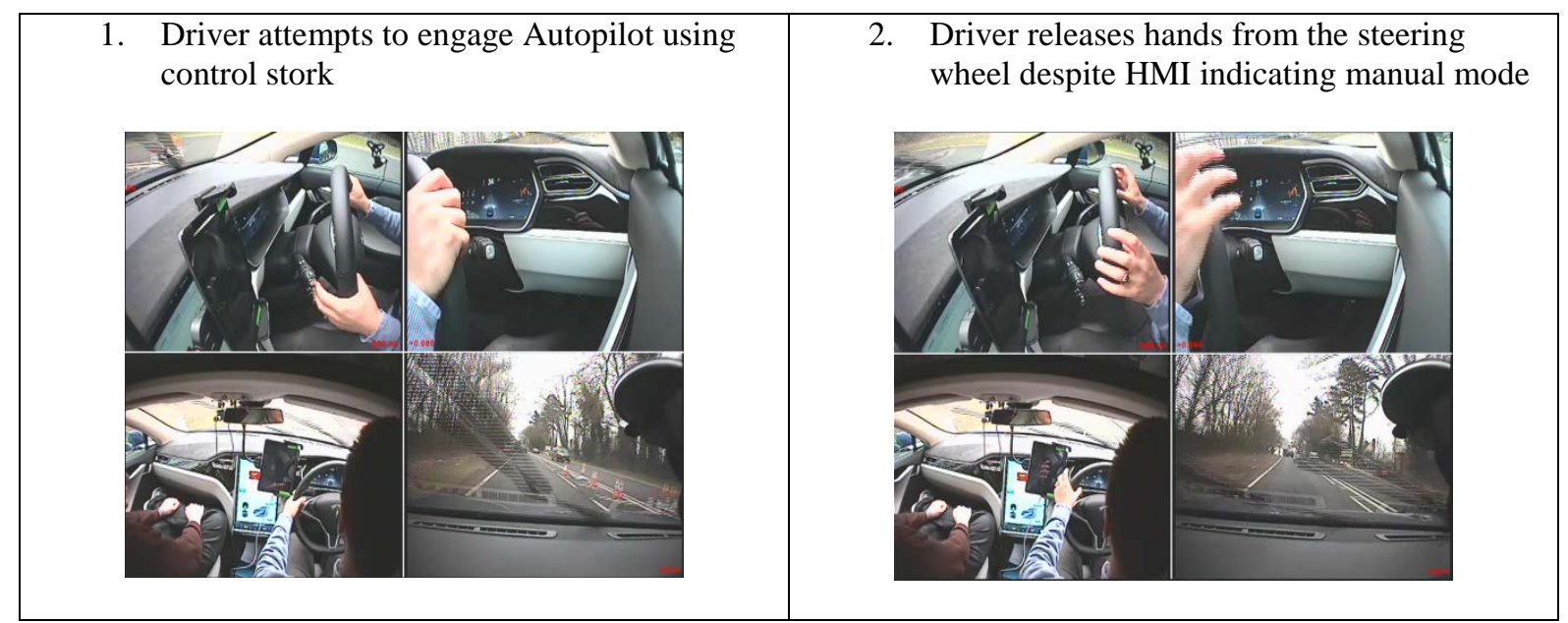

Figure 4. Storyboard indicating a failure to engage Autopilot

\section{Engagement in non-driving related secondary tasks}

Whilst only a small number of examples for engagement in non-driving related secondary tasks were evident within the data, it is clear that Tesla's Autopilot may indeed encourage 'risky' behaviour for some individuals. In the storyboard presented in Figure 5, the vehicle was driving in Autopilot mode. The driver proceeded to drink coffee for approximately 11 seconds whilst completely "hands off". Whilst the duration of the task is relatively short, the driver's posture suggested that they were not attending to the road environment in any capacity. Whilst the driver may have felt it was safe to engage in this non-driving related secondary task due to the carriageway being clear of other traffic, a sudden change within the roadway ahead could have prompted an emergency take over request. In terms of driver roles, this would represent a sudden control transition taking the driver from a DND to a DD (Banks \& Stanton, 2017). This could result in a 'startle' effect (Sarter et al, 1997), resulting in a DD being ill-prepared to regain control. Of course, drinking coffee could be seen as an arbitrary example of a non-driving related secondary task, especially as drivers of manual vehicles may be guilty of doing the same. However, the key difference between manual and automated driving is that the driver can become "hands free" and therefore may not be in as good a position to quickly resume control.

There were other instances whereby the same driver was also trying to engage the Experimenter in conversation that led to a shift in body posture (i.e. the driver turned around for a few seconds). This differed from similar situations in manual driving as the driver did not make any glances back to the road environment and their gaze was firmly fixed to the rear of the vehicle. Overall system safety could be deemed as compromised as the driver was not attending to the otherwise dynamically changing environment ahead of them.

It is clear then that the role of DND poses a real risk to overall system safety, even for SAE Level 2 systems. This is a pertinent research finding as it adds to the growing body of literature that shows that drivers are at risk of becoming disengaged from the driving task, both for momentary and prolonged periods during automated phases of driving (e.g. Cabrall et al, 2016; Endsley, 2017; Heikoop et al, 2017; Kyriakidis et al, 2017). The role of the driver is likely to shift throughout the duration of a journey between DD, DM and DND (Banks \& Stanton, 2017). Whilst there have been a number of recommendations put forward to help 
improve the design of SAE Level 2 systems (e.g. Banks \& Stanton, 2015; Endsley, 2017), there needs to be a better balance between the risks associated with automation misuse and the pursuit of improved driver experience.

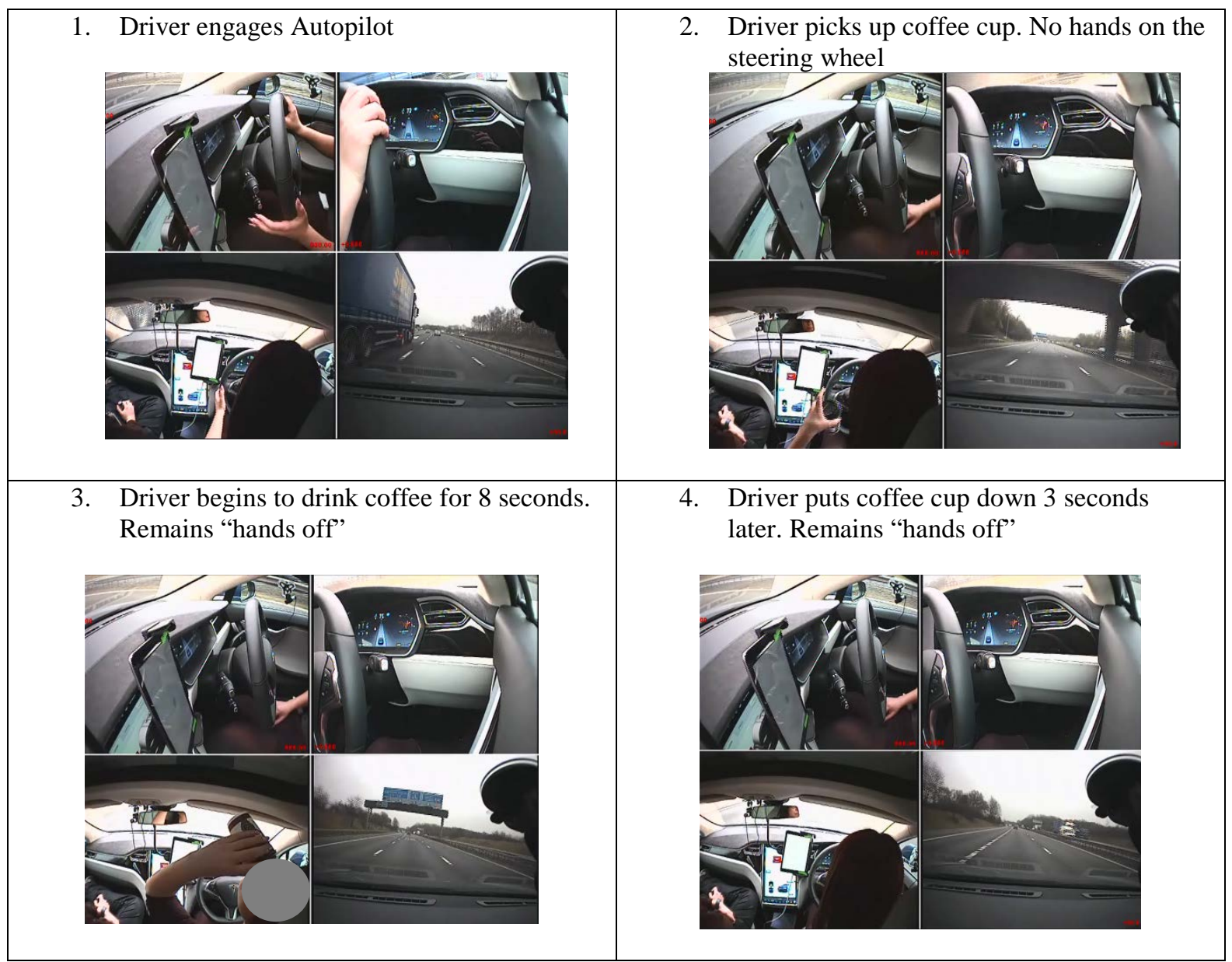

Figure 5. Evidence that a driver transitioned to the role of DND during Autopilot mode

\section{Discussion}

Our study shows that the engagement of Autopilot led most drivers to assume the role of a DM. However, potential performance issues were highlighted via a thematic analysis of video data. If we consider that the purpose of Eriksson et al's (2017) study was to investigate how drivers pace the control transition process following a non-urgent request to resume control, drivers were encouraged and motivated to remain in an active monitoring state. Our findings suggest that on the whole, drivers were happy to become completely "hands and feet free" and only placed their hands back on the wheel as a result of system warnings. With the literature suggesting that prolonged exposure to highly automated driving conditions can lead to significant driver disengagement (Stanton et al, 1997; Young and Stanton, 2002; Saxby et al, 2007), it seems reasonable to assume that drivers could easily engage in a non-driving related secondary task that could distract them from their DM role. Inappropriate levels of trust represent an enduring challenge for system designers (Walker et al, 2016). With one driver exclaiming "it is so easy to get used to this", it is clear that the intermediate phases of 
automation may be plagued by an underlying 'trust problem' that heavily influences their performance on the vigilance task associated with the DM role. This is a difficult issue to address, especially when we consider that in order for automated features to become commercially viable, they must be accurate, reliable, predictable and dependable (e.g. Eriksson \& Stanton, 2017; Donmez et al, 2006). It is these factors after all that contribute to the development of trust. If a system behaves in a consistent and reliable manner for prolonged periods, the user of that system can become complacent in its operation (e.g. Parasuraman et al, 1993; Lee \& See, 2004; Hollnagel \& Woods, 2005) and may not respond appropriately when required (e.g. Stanton et al, 1997; Hancock, 2013). Inappropriate levels of trust in automation have therefore created new pathways for driver error to occur (Stanton and Salmon, 2009; Walker et al, 2015). In terms of driving automation, a driver may not monitor the system as closely as is warranted due to the perception of high system reliability. This lapse in performance should not however be seen as "driver error" - instead it signals a much larger “design error” whereby the sociotechnical system fails (Chapanis, 1999; Stanton and Baber, 2002). This stems from the viewpoint that the driver and automated systems must coordinate their behaviour in order to maintain effective performance (e.g. Stanton et al, 2006; Salmon et al, 2009, 2016; Eriksson \& Stanton, 2017).

Banks et al, (2014) showed how cognitive functions can be distributed between drivers and automation in contemporary Level 2 vehicle systems. Human drivers and automated vehicles possess differing types of awareness about the ambient traffic situations (Stanton et al, 2017). Human drivers understand much more about the motivations and potential actions of other drivers (Walker et al,2015) whilst automated systems can possess much more accurate metrical information about kinematics such as range and rate change to other vehicles (Young et al, 2007; Stanton \& Salmon 2009). Automated systems have the potential to enhance driver situation awareness but at the same time, humans are notoriously bad at completing sustained monitoring tasks. Decay in performance is highly likely (Stanton, 2015). With this in mind the authors of this paper argue that a shift in attitude is required to ensure that the role of the driver within automated driving systems is protected. Tesla, along with other vehicle manufacturers, have designed vehicles that can essentially drive themselves most of the time but still require a human driver to monitor its performance and intervene when necessary. This design ethos has led to a situation in which humans are bound to fail and so “driver error” becomes an inevitable outcome (Stanton \& Baber, 2002). Systems designers have created an impossible task (Stanton, 2015) - one that requires the driver to remain vigilant for extended periods. The literature openly reports that humans are poor at doing this (e.g. Molloy \& Parasuraman, 1996). With this in mind, whilst strategies to help improve Level 2 systems could be explored, it seems more appropriate at this time to accept that the DD and DND roles are the only two viable options that can fully protect the role of the human within automated driving systems. This in turn means that either the human driver should remain in control of longitudinal and/or lateral aspects of control (i.e. one or the other) or they are removed entirely from the control-feedback loop (essentially moving straight to SAE 4). In the latter instance, this places increased pressure on systems designers to ensure that their systems are both reliable and failsafe before being commercialised (Kalra \& Paddock, 2016). Using the driver as the last line of defence is arguably a poor solution for addressing the shortcomings in the design and implementation of SAE Level 2 and 3 automation. 


\section{Evaluation and future research}

It is important to acknowledge that there were a number of practical constraints that limited the feasibility of data collection in this study. These were primarily concerned with the availability of the test vehicle and hence culminated with the recruitment of a small sample and limited drive durations (approximately 40 minutes). However, the authors argue that despite these limitations, worrisome behaviour was still observed. This is an important finding because if behaviours like these can be demonstrated following relatively short exposure to enhanced Level 2 systems, it is likely that these behaviours will be further exaggerated with increased exposure. Even so, future research should adopt a longitudinal approach, with a larger sample size, whereby the same participants are exposed to the same journey multiple times to test this hypothesis. This will also enable a deeper analysis of emergent behaviour during enhanced Level 2 driving.

The addition of eye tracking would also further complement the data as it would enable analysts to properly assess the visual behaviour of drivers and could be used to infer levels driver distraction and inattention resulting from automation implementation (e.g. Merat et al. 2014). For example, eye tracking data would be able to confirm "where" drivers were looking when the Autopilot initiated the 'hold steering wheel' warning on the internal HMI.

Overall, despite its limitations, this study offers a unique insight into real-world driver behaviour using enhanced Level 2 systems. This adds to the growing body of literature relating to on-road driver behaviour within the driving automation domain (e.g. Banks \& Stanton, 2015, 2016; Eriksson et al. 2017; Endsley, 2017; Naujoks et al. 2016; Stapel et al. 2017).

\section{Acknowledgements}

This research has been conducted as part of the European Marie Curie ITN project HF Auto Human Factors of Automated Driving (PITN-GA-2013-605817).

\section{References}

Banks, V. A., \& Stanton, N. A. (2015). Discovering driver-vehicle coordination problems in future automated control systems: Evidence from verbal commentaries. Procedia Manufacturing, 3, 2497-2504.

Banks, V. A., \& Stanton, N. A. (2016). Keep the driver in control: Automating automobiles of the future. Applied Ergonomics, 53(B), 389-395.

Banks, V. A., \& Stanton, N. A. (2017). Analysis of driver roles: Modelling the changing role of the driver in automated driving systems using EAST. Theoretical Issues in Ergonomics Science. 
Banks, V. A., Stanton, N. A., \& Harvey, C. (2014). What the drivers do and do not tell you: using verbal protocol analysis to investigate driver behaviour in emergency situations. Ergonomics, vol 57, no 3, pp 332-342.

Bailey, N.R. and Scerbo, M.W., Automation-induced complacency for monitoring highly reliable systems: The role of task complexity, system experience, and operator trust. Theoretical Issues in Ergonomics Science, 8 (4), 2007, 321-348.

Cabrall, C., Happee, R., \& de Winter, J. (2016). From Mackworth’s clock to the open road: A literature review on driver vigilance task operationalization. Transportation Research Part F: Traffic Psychology and Behaviour, vol 40, pp 169-189.

Casner S. M. and Schooler, J.W. Vigilance impossible: Diligence, distraction, and daydreaming all lead to failures in a practical monitoring task. Consciousness and Cognition, 35, 2015, 33-41.

Chapanis, A. (1999). The Chapanis Chronicles. Aegean, Santa Barbara.

Damböck, D., Bengler, K., Farid, M., \& Tönert, L. (2012). Übernahmezeiten beim hochautomatisierten Fahren. Tagung Fahrerassistenz. München, vol 15, pp 16.

Department for Transport. (2015). The Highway Code. Available at: https://www.gov.uk/guidance/the-highway-code. Accessed 9 Aug 2017.

Department for Transport. (2017). Statistical release of the National travel survey: England 2016. Available at: https://www.gov.uk. [Accessed 17.10.2017].

Donmez, B., Boyle, L. N., \& Lee, J. D. (2007). Safety implications of providing real-time feedback to distracted drivers. Accident Analysis and Prevention, vol 39, no 3, pp. 581-90.

Dozza, M. (2012). What factors influence drivers' response time for evasive maneuvers in real traffic? Accident Analysis \& Prevention, vol 58, pp 299-308.

Endsley, M. R. (1995). Toward a theory of situation awareness in dynamic systems. Human Factors, 37(1), 32-64.

Endsley, M. R. (2017). Autonomous driving systems: A preliminary naturalistic study of the Tesla Model S. Journal of Cognitive Engineering and Decision Making, DOI: $10.1177 / 1555343417695197$.

Eriksson, A. (2017). Control Transitions in Highly Automated Vehicles. Doctoral Dissertation, University of Southampton.

Eriksson and Stanton (2017). "The Chatty Co-Driver: A Linguistics Approach Applying Lessons Learnt from Aviation Incidents." Safety Science, 99, 94-101.

Eriksson, A., Banks, V. A., \& Stanton, N. A. (2017). Transition to Manual: comparing simulator with on-road control transitions. Accident Analysis \& Prevention, vol 102C, pp 227-234.

Eriksson, A., \& Stanton, N. A. (2017). Take-over time in highly automated vehicles: noncritical transitions to and from manual control. Human Factors. 59(4): 689-705.

Gasser, T. M., \& Westoff, D. (2012). BASt-study: Definitions of automation and legal issues in Germany. Presentation at the 2012 Road Vehicle Automation Workshop, 24-26 July 2012, Irvine, California.

Gold, C., Damböck, D., Lorenz, L., \& Bengler, K. (2013). “Take over!” How long does it take to get the driver back into the loop? Proceedings of the Human Factors and Ergonomics Society Annual Meeting, vol 57, no 1, pp 1938-1942.

Gold, C., Korber, M., Lechner, D., \& Bengler, K. (2016). Taking Over Control From Highly Automated Vehicles in Complex Traffic Situations: The Role of Traffic Density. Human Factors, vol 58, no 4, pp 642-652. 
Hancock, P. A. (2015). Automobility: the coming use of fully-automated on-road vehicles. Paper presented at the Cognitive Methods in Situation Awareness and Decision Support (CogSIMA), 2015 IEEE International Inter-Disciplinary Conference on.

Hancock, P. A. (2013) In search of vigilance. American Psychologist, vol 68 no 2, pp. $97-$ 109.

Heikoop, D. D., de Winter, J. C., van Arem, B., \& Stanton, N. A. (2017). Effects of platooning on signal-detection performance, workload, and stress: A driving simulator study. Applied Ergonomics, vol 60, pp 116-127.

Hollnagel and Woods (2005). Joint Cognitive Systems Foundations of Cognitive Systems Engineering, CRC Press.

Johnson, J. D., Type of Automation Failure: The effects on trust and reliance in automation. Human Factors, 48(18), 2163-2167.

Kalra and Paddock (2016). "Driving to safety: How many miles of driving would it take to demonstrate autonomous vehicle reliability?" Transportation Research Part A: Policy and Practice vol 94, pp. 182-193.

Kircher, K., Larsson, A., \& Hultgren, J. A. (2014). Tactical Driving Behavior With Different Levels of Automation. Ieee Transactions on Intelligent Transportation Systems, vol 15, no 1, pp 158-167.

Körber, M., Gold, C., Lechner, D., \& Bengler, K. (2016). The influence of age on the takeover of vehicle control in highly automated driving. Transportation Research Part F: Traffic Psychology and Behaviour, vol 39, pp 19-32.

Kyriakidis, M., de Winter, J. C. F., Stanton, N., Bellet, T., van Arem, B., Brookhuis, K., et al, (2017). A human factors perspective on automated driving. Theoretical Issues in Ergonomics Science, pp 1-27.

Lee, J. D. \& See, K. A. (2004). Trust in automation: Designing for appropriate reliance. Human Factors, vol 46, pp. 50-80.

Lombard, M., Snyder-Duch, J., Bracken, C.C., 2002. Content analysis in mass communication. Assessment and reporting of intercoder reliability. Human Communication Research, vol 28, no 4, 587-604.

Louw, T., Merat, N., \& Jamson, H. (2015). Engaging with Highly Automated Driving: To be or Not to be in the Loop? Paper presented at the 8th International Driving Symposium on Human Factors in Driver Assessment, Training and Vehicle Design, At Salt Lake City, Utah, USA.

Lu, Z., Coster, X., \& de Winter, J. (2017). How much time do drivers need to obtain situation awareness? A laboratory-based study of automated driving. Applied Ergonomics, vol 60, pp 293-304.

Marques, J. F., \& McCall, C. (2005). The application of inter-rater reliability as a solidification instrument in a phenomenological study. The Qualitative Report, vol 10 no 3, 439-462.

Merat, N., Jamson, A. H., Lai, F. F. C. H., Daly, M., \& Carsten, O. M. J. (2014). Transition to manual: Driver behaviour when resuming control from a highly automated vehicle. Transportation Research Part F: Traffic Psychology and Behaviour, vol 26, Part A, pp 1-9.

Mercedes-Benz. (2013). Distronic Plus with Steering Assist. Available at https://www.mercedes-benz.com. [Accessed 17.10.2017].

Metzger, U., \& Parasuraman, R. (2005). Automation in future air traf- fic management: Effects of decision aid reliability on controller performance and mental workload. Human Factors, vol 47, pp 35-49 
Michon, J.A. (1985). A critical view of driver behavior models: what do we know, what should we do? In: Evans, L., Schwing, R.C. (Eds.), Human Behavior and Traffic Safety. Plenum Press, New York, pp 485-520.

Molloy, R., \& Parasuraman, R. (1996). Monitoring an automated system for a single failure: Vigilance and task complexity effects. Human Factors, vol 38, pp 311-322

National Highway Traffic Safety Administration. (2013). Preliminary Statement of Policy Concerning Automated Vehicles.

National Highway Traffic Safety Administration. (2017). ODI Resume. Available at https://static.nhtsa.gov/odi/inv/2016/INCLA-PE16007-7876.PDF

Naujoks, F., Purucker, C., \& Neukum, A. (2016). Secondary task engagement and vehicle automation-Comparing the effects of different automation levels in an on-road experiment. Transportation research Part F: Traffic Psychology \& Behaviour, 38, 6782.

Norman, D. A. (1990). The "problem" with automation: inappropriate feedback and interaction, not "over-automation". Philosophical Transactions of the Royal Society of London - Series B: Biological Sciences, vol 327, no 1241, pp 585-93.

Parasuraman, R., Molloy, R., \& Singh, I. L. (1993). Performance consequences of automation-induced 'complacency'. The International Journal of Aviation Psychology, vol 3, pp 1-23.

Parasuraman, R., \& Riley, V. (1997). Humans and automation: Use, misuse, disuse, abuse. Human Factors: The Journal of the Human Factors and Ergonomics Society, vol 39 no 2, pp 230-253.

Radlmayr, J., Gold, C., Lorenz, L., Farid, M., \& Bengler, K. (2014). How Traffic Situations and Non-Driving Related Tasks Affect the Take-Over Quality in Highly Automated Driving. Proceedings of the Human Factors and Ergonomics Society Annual Meeting, vol 58, no 1, pp 2063-2067.

Robert Bosch Gmbh. (2015). SMMT Connected - Automated Driving - Industry Perspective. Available at https://www.smmt.co.uk. [Accessed 17.10.2017].

SAE J3016. (2016). Taxonomy and Definitions for Terms Related to Driving Automation Systems for On-Road Motor Vehicles, J3016_201609: SAE International.

Salmon, P. M., McClure, R. and Stanton, N. A. (2012) Road transport in drift? Applying contemporary systems thinking to road safety, Safety Science, 50 (9), 1829-1838.

Salmon, P.M., Stanton, N.A., Walker, G.H., \& Jenkins, D.P. (2009). Distributed Situation Awareness: Advances in Theory, Measurement and Application to Teamwork. Ashgate: Aldershot, UK.

Salmon, P. M., Walker, G. H. \& Stanton, N. A. (2016) Pilot error versus sociotechnical systems failure: a distributed situation awareness analysis of Air France 447. Theoretical Issues in Ergonomics Science, vol 17 no 1, pp 64-79.

Sarter, N. B., \& Woods, D. D. (1995). How in the world did we ever get into that mode? Mode error and awareness in supervisory control. Human Factors, vol 37, pp. 5-19.

Sarter, N. B., Woods, D. D., \& Billings, C. E. (1997). Automation Surprises. In G. Salvendy (Ed.), Handbook of Human Factors \& Ergonomics (second edition ed.): Wiley.

Saxby, D. J., Matthews, G., Hitchcock, E. M., \& Warm, J. S. (2007). Development of active and passive fatigue manipulations using a driving simulator. Human Factors, vol 51 no 18, pp 1237-1241.

Seppelt, B.D., \& Victor, T.W. (2016). Potential Solutions to Human Factors Challenges in Road Vehicle Automation. Road Vehicle Automation 3 (Eds.), G. Meyer S. Beiker. 131-147. Berlin: Springer.

Stanton, N. A. (2015). Responses to Autonomous Vehicles. Ingenia, 9. 
Stanton, N. A. and Baber, C. (2002) Error by design: methods for predicting device usability. Design Studies, 23, 363-384.

Stanton, N. A. and P. M. Salmon (2009). Human error taxonomies applied to driving: A generic driver error taxonomy and its implications for intelligent transport systems. Safety Science, 47 (2), 227-237.

Stanton, N. A., Salmon, P. M., Walker, G. H., Hancock, P. A. and Salas, E. (2017) State-ofscience: Situation awareness in individuals, teams and systems. Ergonomics, Manuscript, 60 (4), 449-466.

Stanton, N., Young, M., \& McCaulder, B. (1997). Drive-by-wire: the case of mental workload and the ability of the driver to reclaim control. Safety Science, vol 27, no 23, pp 149-159.

Stapel, J., Mullakkal-Babu, F. A., \& Happee, R. (2017). Driver behaviour and workload in an on-road automated vehicle. Road Safety \& Simulation International Conference, 1719 Oct 2017, Hague, NL.

Tesla Motors. (2016a). Model S Software Version 7.0. https://www.tesla.com/en_GB/presskit/autopilot.

Tesla Motors. (2016b). Model S Owner's Manual. Available at: https://www.tesla.com/sites/default/files/model_s_owners_manual_north_america_en _us.pdf. Accessed 9 Aug 2017.Thomas, L. C., \& Wickens, C. D. (2004). Eye-tracking and individual differences in off-normal event detection when flying with a synthetic vision system display. Proceedings of the Human Factors and Ergonomics Society 48th Annual Meeting (pp. 223-227). Santa Monica, CA: Human Factors and Ergonomics Society.

United Nations. (1968). Vienna Convention on Road Traffic. Available at: https://www.unece.org/fileadmin/DAM/trans/conventn/crt1968e.pdf [Accessed 15.05.2017].

Volvo Cars. (2016). Intellisafe Autopilot. http://www.volvocars.com/intl/about/ourinnovation-brands/intellisafe/intellisafe-autopilot.

Walker, G. H., Stanton, N. A., \& Salmon, P. M. (2015). Human factors in automotive engineering and technology. Ashgate: Aldershot, UK.

Walker, G. H., Stanton, N. A. and Salmon, P. M. (2016) Trust in vehicle technology. International Journal of Vehicle Design, vol 70, no 2, pp 157-182.।

Young, M. S. and Stanton, N. A. (2002). Malleable Attentional Resources Theory: A new explanation for the effects of mental underload on performance. Human Factors, 44 (3), 365-375.

Young, M. S., \& Stanton, N. A. (2007). Back to the future: brake reaction times for manual and automated vehicles. Ergonomics, vol 50, no 1, pp 46-58.।

Young, M. S., Stanton, N. A. and Harris, D. (2007). Driving automation: Learning from aviation about design philosophies. International Journal of Vehicle Design, 45 (3), 323-338.

Zeeb, K., Buchner, A., \& Schrauf, M. (2015). What determines the take-over time? An integrated model approach of driver take-over after automated driving. Accident Analysis \& Prevention, vol 78, pp 212-221. 